\title{
Male Out-Migration and its Impact on Women Empowerment in West Bengal
}

\author{
Kingsuk Maity ${ }^{1 *}$, Debasis Mazumdar ${ }^{2}$ and Pinaki Das ${ }^{3}$ \\ ${ }^{1}$ Department of Economics, Shibpur Dinobundhoo Institution (College), West Bengal, India \\ ${ }^{2}$ Department of Economics, The Heritage College, Kolkata, India \\ ${ }^{3}$ Department of Economics, Vidyasagar University, West Bengal, India \\ "Corresponding author: kingsuk1974@yahoo.co.in
}

\begin{abstract}
In this paper, an attempt has been made to measure the empowerment of women in terms of sustained increase in income earning capacity accompanied by a freedom of choice in families which have come across out-migration of male members. This measure of empowerment of women is mainly based on three indicators, viz. restrictions placed on them, their decision-making powers and their mobility. This study shows that out-migration of male members has not generated any significant impact on the empowerment of women members of those families. The most general factors which increase mobility of women, the decision-making power and relatively less social restrictions placed on them are age, their education, marital duration, residential status and occupation.
\end{abstract}

Keywords: out- migration, women empowerment, mobility.

JEL Classification: D1, J16, R23.

Women empowerment has become a major concern for the policy makers in the developing world since it has been emerging as an important indicator of economic development of a society. The socioeconomic status of women in any society can influence and are also being influenced by their opportunities to access better education, training and health facilities. Such a low level of women empowerment is not only detrimental to the female members of a family; it affects the living standard of the whole family and extends to the community as a whole. An enhancement of active agency of women can, in many circumstances, adding substantially to the lives of all people - all members of the family. The enhancement of capabilities of women not only contribute women's own freedom and well-being, but also has many other positive externalities (Sen, 2001).Thus, the process of empowerment begins at the level of a woman's individual consciousness and becomes externalized through remunerated labour, greater physical mobility a strong role in the household and, eventually, meaningful participation in the wider community (Schuler and Hashemi, 1993).

\section{Literature review}

The patriarchal structures of the society in many parts of India often cause the subjugation of women workforce to their male counterparts. Thus, women, whether young or adult, occupy a secondary status compared to their male counterparts in Indian society. That economic factors play an important role in women empowering have been reflected in many research works (Duflo, 2003). However, given the cultural and social constraints imposed on women in India, economic factors alone do not determine the complete periphery of women empowerment. As a result, an inducement of this empowerment, though requires economic interventions, should be adequately supplemented by other initiatives of development such as political quotas, education, awareness of property rights etc. (Deshmukh-Ranadive, 2003). 
The Millennium Development Goals have also emphasized the essential role of gender equity and women's empowerment, as an essential tool for achieving acceptable demographic changes in developing countries. The World Bank has suggested that empowerment of women should be the principal feature of all social development programmes in any country.

Such empowerment, however, needs a balance between factors expressed in terms of decisionmaking power from the perspectives of health, mobility and household purchases and an access to work and education. Several studies have shown that women may be empowered in one area of life while many other areas may remain untouched (Hashemi et al. 1996; Malhotra and Mather 1997). Let us take into account the migration decision taken by the male members or the male family heads and its possible consequence upon the female members of any household, particularly in terms of their changed domain of choice and decision making power.

In most cases, it has been observed that the wife is left with in-laws or with parents and other relatives after the out-migration of her husband to distant places in search of jobs. It is rare that the woman and children are left behind alone (Gulati 1993; citing Parasuraman 1986).

Hence, for the female members the need for help and guidance becomes crucial in the period immediately after the migrant's first departure (Gulati 1993).

Acosta's study on El Salvador determines households receiving remittances from selfbusinesses, compared with non-remittancesreceiving households. Receiving remittances was significantly associated with the probability of female ownership (Acosta 2007).

Women's empowerment is a major concern in the developing world and is emerging as an important indicator of the development of a society as well as the status of women. The findings of this study show that out-migration of men has not had a significant impact on the emancipation of women (Sinha et al. 2012).

\section{Rationale for our study}

In this study we aim at studying the changed status of women in families which have experienced the migration of male adults and investigate the factors that determine their empowerment. The theoretical structure of this study is based on the work of Amin et al. (1998) which splits the concept of women's empowerment into three components: (i) the inter-spouse consultation index, which seeks to represent the extent to which husbands consult their wives in household affairs; (ii) the individual autonomy index, which represents women's selfreported autonomy of physical movement outside the house and in matters of spending money; and (iii) the authority index, which reports on actual decision-making power.

The incidence of migration of one or more family members will obviously influence the way the family functions. The absence of particular family members, either on a permanent or temporary basis, will break the hegemony in family structure, both in destination and origin areas.

These perceived notions might be different in different socio-economic or socio-cultural environment, and from this view point, this study in the backward districts of West Bengal seems to be justified. The objective of the present study is to determine the factors affecting women's empowerment in terms of their decision-making powers, mobility and economic control.

The present study sets out to understand the following before moving on to the specific analysis of migration:

(1) Influencing factors of women empowerment;

(2) Levels of women's independent decision making in different aspects of life such as household purchases, money handling and mobility; and

(3) socio-economic variations in the level of empowerment.

\section{Data and Methodology}

Empowerment of women, expressed in terms of decision-making powers in health, mobility, household purchases etc., portrays one important phase of women's capability and autonomy particularly in any household. This study is based on primary data and the sample households have been selected purposively from four relatively 
backward districts of West Bengal (Paschim Medinipur, Puruliya, Murshidabad and South-24 Parganas), and the subsequent investigation has been carried out in between September, 2013 to April, 2014 (questionnaire is based on the NFHS3, 2005-06). The sample size is 640 indicating the families which have experienced male out-migration and these are collected from 8 sample Blocks, and 32 sample villages of those four districts.

In this study women belonging to families experiencing male out-migration were the unit of analysis. The data did not give details about those women left behind due to male out-migration directly. In order to identify these women certain control variables were used, namely, 'currently married women' and 'husbands having no other wives'. Further, questions were asked such as: 'Are you living with your husband now or is he staying elsewhere? Here, there were two categories of women, one living with her husband and the other not living with her husband. The latter category has been termed as 'left-behind women' (due to male out-migration). Women were also asked about the duration of the husband's absence. To measure the effects, if any, of migration on the empowerment of 'left-behind women', all those women whose husbands had migrated for less than one year were excluded here. The women were divided into two categories, i.e. wives of migrants and non-migrants. Therefore the total sample size is 640 (consisting of 402 who were the wives of non-migrants and 238 who were the wives of migrants).

Table 1 presents general information about the wives of migrants and non-migrants in West Bengal according to different background characteristics. The variable 'age of women' indicates that the larger proportion of women affected by out-migration fall in the younger age group of 15-34. Age of the husband also shows similar distribution across the two categories. This suggests that there is a greater probability of males migrating at a younger age (leaving their wives behind) as compared to those migrating later in life. Marital duration shows a negative association with migration, i.e. as marital duration increases, the percentage of women left behind due to male out-migration decreases.

Here, $57 \%$ of left-behind wives have no education whereas this figure is $46 \%$ for the wives of nonmigrants. The husband's education shows a similar pattern across the two categories indicating that migration occurs more among people with lower levels of educational attainments and therefore is likely to be a subsistence decision.

Another interesting feature is that there is a greater chance of women in the non-migrant category being employed so out-migration of the husband may not lead to economic freedom for women left behind. The difference in standard of living also augments this fact as a relatively large proportion of wives of non-migrants belong to the high SLI category (Standard of Living Index). This may be due to the fact that a majority of the left-behind wives $(60 \%)$ belong to a non-nuclear household which conforms to kinship patterns where there is a preference among husbands to leave their wives with their parents rather than on their own.

Also, migration appears to be higher among Hindus and other 'backward castes'. Some $89 \%$ of leftbehind wives are from rural areas which indicate the general trend of rural to urban migration, for reasons such as growing shortage of fertile land due to the complex interplay of high population growth, landholding inequality, environmental degradation, rural poverty, and the lack of infrastructure and social services in rural areas. The result of rural out-migration aggravates the deterioration of the rural economy leading to chronic poverty and food insecurity.

Table 1: Distribution of women in migrant and non-migrant categories by women's background characteristics (percentage).

\begin{tabular}{lcc}
\hline Women's characteristics & Non-migrant & Migrant \\
\hline Age of women & 6.7 & 10.1 \\
15-19 & 55.1 & 62.0 \\
20-34 & 38.2 & 27.9 \\
35-49 & & \\
Education & 46.3 & 56.8 \\
No education & 15.5 & 13.7 \\
Primary & 32.0 & 25.3 \\
Secondary & 6.1 & 4.2 \\
Higher & & \\
Husband's education & 26.6 & 26.1 \\
No education & 16.5 & 14.3 \\
Primary & 45.1 & 48.7 \\
Secondary & 11.9 & 10.9 \\
Higher & &
\end{tabular}




\begin{tabular}{lcc} 
Working Women & 36.4 & 29.5 \\
Standard of living & & \\
Low & 24.6 & 32.9 \\
Medium & 33.3 & 34.9 \\
High & 42.0 & 32.1 \\
Household structure & & \\
Non-nuclear & 47.2 & 60.3 \\
Nuclear & 52.8 & 39.7 \\
Marital duration & & \\
0-9 years & 36.9 & 44.9 \\
10-19 years & 33.8 & 33.1 \\
More than 20 years & 29.3 & 22.0 \\
Religion & & \\
Hindu & 72.1 & 66.8 \\
Muslim & 22.4 & 31.3 \\
Others & 5.5 & 1.8 \\
Caste & & \\
General & 31.4 & 28.8 \\
Schedule Caste & 19.5 & 16.2 \\
Schedule Tribes & 8.8 & 3.0 \\
Other Backward Castes & 40.2 & \\
\hline N = Total & 402 & \\
\hline
\end{tabular}

Source: Sample Survey.

There are government policies, like the National Agriculture Policy (2000), which discourage migration from rural areas but these measures have not proven to be effective in reversing or stalling the trend. So, it can be concluded that younger women, with shorter marital duration, belonging to Hindu and other 'backward castes' are those whose husbands out-migrate leaving them in a non-nuclear household.

Our measure of women's empowerment is based mainly on three indicators, viz. their decisionmaking powers, restrictions placed on them by their husband and their mobility. Each of these indices provides a different dimension of empowerment. The decision-making index is a sum of the scores assigned to women's responses to questions regarding their voice in certain spheres such as her own health, household purchases (for satisfying both long-term and short-term needs), and decisions over the usage of her husband's earnings. On the basis of such scores, women are divided into three categories of low, medium and high level decisionmaking powers. Similarly, indices for restrictions and mobility have been constructed.

\section{Construction of the Women Empowerment Index}

\section{Decision-making power of women}

This variable is computed on the basis of certain questions asked during the survey to the respondent.

1. Final decision on her own healthcare.

2. Final decision on making large household purchases.

3. Final decision on making household purchases for daily needs.

4. Final decision on visits to her family or relatives.

5. Final decision on deciding what to do with the money husband earns.

The responses to the above questions are in three categories, i.e. 'husband or any other person', 'respondent and husband together' and 'respondent alone'. Those women who responded that they take decisions 'alone' are given a value of 2 and if they answered 'jointly' take the decision then a value of 1 is given. If the decision is taken by 'husband or someone else' then a value of 0 is given. After giving the values of 0,1 and 2, scores for every woman are calculated. Women getting a score of 0 are categorized as 'no decision power', $1-5$ as 'medium decision-making power' and 6-10 as 'high decision-making power'.

\section{Freedom of mobility}

In the sample survey, three questions have been put for the estimation of freedom of mobility of the female member. This is stated below:

'Are you usually allowed to go to the following places alone, only with someone else or not at all?'

(a) Market

(b) Health facility

(c) Places outside village or community.

The responses to the above questions are put into three categories (i.e. 'respondent alone', 'with someone else' and 'not at all'). Those women who responded that they are allowed 'alone' are given a value of 2 and if they are allowed 'with someone else' then a value of 1 is given. If they are 'not at all allowed' then a value of 0 is given. After giving 
the values of 0,1 and 2, scores for every woman are calculated. Women getting a score of 0 are categorized as 'low', 1-3 as 'medium' and 4-6 as 'high' mobility.

\section{Restrictions by husband}

In the sample survey, this variable has also been estimated on the basis of three questions as shown below:

1. Husband does not permit her to meet her female friends.

2. Husband tries to limit her contact with family.

3. Husband insists on knowing where she is.

Those who responded ' $\mathrm{No}^{\prime}$ are given a value of 1 whereas if respondents reported 'Yes' they are given a value of 0 . After giving the values of 0 and 1 , scores for every woman are calculated. Women getting a score of 0 are categorized as having 'high restrictions', 1-2 'medium restrictions' and 3 as 'no restrictions by husband'.

Ten predictor variables are used in the analysis. All predictor variables are categorical. The predictor variables are: age of the woman in years (15-19, 2034, 35-49); women's education (primary, secondary or higher); husband's education (primary, secondary or higher); marital duration (0-9 years, 10-19 years and 20 years); residence (urban, rural); household structure (nuclear and non-nuclear/extended); standard of living index (low, medium and high, based on ownership of assets and other amenities); religion (Hindu, Muslim, other); caste/tribe (SC/ST, General and OBC).

\section{RESULTS AND DISCUSSION}

Based on sample data, from which information was collected on the magnitude of a wife's participation in household decision making, women's control over resources, restrictions by the husband and freedom of movement, the following tables show the results of the multivariate analysis on each of these indicators of women's empowerment.

Table 2 presents the percentage of women (those living with their husband and those not living with their husband) with three levels of decisionmaking power, according to selected background characteristics. Taking the category of women who are living with their husbands, there is an increase in decision-making powers with increases in age, educational attainment and marital duration of the women. With increased levels of educational attainment in the husband and the standard of living of the family, decision- making powers in women appear to decline, corroborating the patriarchal kinship structure. Where a woman has economic freedom (i.e. when she is working), she has more decision-making powers as compared to those women who are not working. Urban residence exposes women to liberal ideologies enabling higher levels of decision-making powers as compared to their rural counterparts. Similarly, a woman living in a nuclear household may enjoy greater freedom and hence decision-making powers than those women who are living in an extended family. This may be as a result of the necessity of running the family or of a more genuinely, progressive outlook.

Migration of male members of the family does not appear to significantly change the decision-making powers of the women left behind. Analysis of such women against background characteristics shows similar patterns to those of non-migrant families, i.e. age and marital duration has a positive impact on the decision-making powers of women whereas a husband's education and standard of living has a negative impact on the decision-making powers of women. The percentages of women enjoying higher levels of decision-making powers are much higher for these categories as compared to those women who live in rural areas who do not work outside the home and live in a non-nuclear/extended family. The study also revealed that women belonging to other religions and the general category have higher decision- making power when compared to Hindu or Muslim women or women of SC, ST.

Table 3 presents the percentage of women (those living with their husband and those not living with their husband) with three levels of freedom of mobility, according to selected background characteristics. With an increase in age, educational attainment and marital duration of the women, the percentage with high levels of freedom of mobility is increased in both migrant and non-migrant households. As expected, women who are working, and who live in urban areas and in nuclear families, experience higher levels of freedom of mobility than their counterparts in the respective categories. 
Table 2: Percentage of women with different levels of decision-making power by migrant status and background characteristics (2013-14)

\begin{tabular}{|c|c|c|c|c|c|c|}
\hline \multirow[t]{2}{*}{ Background characteristics } & \multirow[b]{2}{*}{ Low } & \multicolumn{2}{|c|}{$\begin{array}{l}\text { Living with husband } \\
\text { (non-migrant } \mathrm{HH} \text { ) }\end{array}$} & \multicolumn{3}{|c|}{$\begin{array}{c}\text { Not living with husband } \\
\text { (migrant HH) }\end{array}$} \\
\hline & & Medium & High & Low & Medium & High \\
\hline \multicolumn{7}{|l|}{ Age of women (in years) } \\
\hline $15-19$ & 18.8 & 68.9 & 12.3 & 10.0 & 51.5 & 38.5 \\
\hline $20-34$ & 10.6 & 66.4 & 23.0 & 5.9 & 45.5 & 48.6 \\
\hline $35-49$ & 8.5 & 63.8 & 27.6 & 3.9 & 42.4 & 53.7 \\
\hline \multicolumn{7}{|l|}{ Marital duration } \\
\hline 0-9 years & 13.5 & 67.1 & 19.4 & 11.8 & 52.6 & 35.5 \\
\hline 10-19 years & 8.8 & 64.9 & 26.3 & 4.8 & 39.1 & 56.0 \\
\hline More than 20 years & 7.9 & 63.9 & 28.2 & 1.1 & 34.1 & 64.8 \\
\hline \multicolumn{7}{|l|}{ Household structure } \\
\hline Non-nuclear & 14.1 & 65.5 & 20.4 & 16.1 & 47.5 & 36.4 \\
\hline Nuclear & 7.5 & 65.2 & 27.3 & 0.8 & 34.3 & 64.9 \\
\hline \multicolumn{7}{|l|}{ Education of women } \\
\hline No education & 13.9 & 65.9 & 20.2 & 8.4 & 41.0 & 50.6 \\
\hline Primary & 11.1 & 64.7 & 24.2 & 4.3 & 48.4 & 47.3 \\
\hline Secondary & 8.4 & 65.3 & 26.3 & 4.4 & 47.5 & 48.2 \\
\hline Higher & 4.1 & 64.0 & 32.0 & 1.3 & 48.5 & 50.3 \\
\hline \multicolumn{7}{|l|}{ Wife currently working } \\
\hline No & 10.6 & 66.8 & 22.6 & 5.7 & 47.3 & 47.0 \\
\hline Yes & 9.1 & 64.0 & 27.0 & 4.5 & 39.8 & 55.6 \\
\hline \multicolumn{7}{|l|}{ Standard of living } \\
\hline Low & 9.1 & 65.0 & 25.9 & 4.0 & 45.9 & 50.2 \\
\hline Medium & 10.4 & 65.0 & 24.7 & 5.5 & 43.6 & 50.9 \\
\hline High & 10.2 & 66.7 & 23.1 & 6.1 & 45.5 & 48.4 \\
\hline \multicolumn{7}{|l|}{ Religion } \\
\hline Hindu & 10.7 & 66.1 & 23.2 & 6.5 & 45.1 & 48.4 \\
\hline Muslim & 11.7 & 65.3 & 23.0 & 5.3 & 47.9 & 46.8 \\
\hline Others & 5.8 & 63.4 & 30.8 & 0.8 & 32.4 & 66.8 \\
\hline \multicolumn{7}{|l|}{ Caste } \\
\hline General & 10.1 & 65.4 & 24.5 & 4.7 & 42.8 & 52.5 \\
\hline SC & 9.2 & 65.6 & 25.2 & 3.8 & 47.0 & 49.3 \\
\hline ST & 8.6 & 67.8 & 23.5 & 2.6 & 52.7 & 44.7 \\
\hline
\end{tabular}

Source: Sample Survey.

However, higher levels of educational attainment in the husband does not translate into greater freedom of mobility for women, indicating that there might be stronger intervening factors exerting a negative influence on the expected outcome of more liberal attitudes with increasing levels of education. Women belonging to other religions have more freedom of mobility than Hindu and Muslim women. Again the differentials among the migrant and non-migrant households are more of degrees than pattern.
Table 4 shows that with an increase in age, educational attainment of the woman and standards of living, restrictions placed on the woman by her husband decrease. Women living in a non-nuclear household have a higher level of restrictions than is experienced by women who live in nuclear families. Women belonging to other religions have fewer restrictions than Hindu and Muslim women. Working women also face fewer restrictions than non-working women. A similar pattern was found among the group of women not living with their 
Table 3: Percentage of women with different levels of freedom of mobility by migrant status and background characteristics

\begin{tabular}{|c|c|c|c|c|c|c|}
\hline \multirow{2}{*}{ Background characteristics } & \multicolumn{3}{|c|}{$\begin{array}{l}\text { Living with husband } \\
\text { (non-migrant } \mathrm{HH} \text { ) }\end{array}$} & \multicolumn{3}{|c|}{$\begin{array}{l}\text { Not living with husband } \\
\text { (migrant } \mathrm{HH})\end{array}$} \\
\hline & Low & Medium & High & Low & Medium & High \\
\hline \multicolumn{7}{|l|}{ Age of women (in years) } \\
\hline $15-19$ & 6.7 & 57.3 & 36.0 & 3.7 & 52.0 & 44.3 \\
\hline $20-34$ & 2.9 & 37.0 & 60.1 & 3.0 & 34.2 & 62.8 \\
\hline $35-44$ & 2.7 & 29.2 & 68.1 & 1.7 & 24.8 & 73.5 \\
\hline \multicolumn{7}{|l|}{ Marital duration (in years) } \\
\hline $0-9$ & 3.7 & 41.8 & 54.6 & 3.9 & 41.0 & 55.2 \\
\hline 10-19 & 2.6 & 31.7 & 65.6 & 2.7 & 27.1 & 70.1 \\
\hline $20 \&$ above & 2.4 & 29.8 & 67.8 & 0.9 & 23.9 & 75.2 \\
\hline \multicolumn{7}{|l|}{ Household structure } \\
\hline Non-nuclear & 3.1 & 39.7 & 57.2 & 4.2 & 40.5 & 55.2 \\
\hline Nuclear & 2.8 & 30.9 & 66.3 & 1.1 & 21.0 & 77.9 \\
\hline \multicolumn{7}{|l|}{ Education of women } \\
\hline No education & 3.0 & 42.6 & 54.5 & 2.9 & 33.4 & 63.7 \\
\hline Primary & 3.3 & 38.1 & 58.6 & 1.6 & 37.4 & 61.1 \\
\hline Secondary & 3.0 & 30.9 & 66.1 & 2.9 & 31.7 & 65.4 \\
\hline Higher & 1.9 & 17.6 & 80.5 & 1.2 & 18.8 & 80.0 \\
\hline \multicolumn{7}{|l|}{ Wife currently working } \\
\hline No & 3.3 & 38.7 & 58.0 & 2.4 & 36.6 & 60.9 \\
\hline Yes & 2.3 & 27.9 & 69.8 & 2.7 & 22.8 & 74.5 \\
\hline \multicolumn{7}{|l|}{ Standard of living } \\
\hline Low & 2.8 & 36.2 & 61.0 & 2.2 & 35.4 & 62.4 \\
\hline Medium & 3.1 & 36.1 & 60.8 & 2.6 & 31.9 & 65.5 \\
\hline High & 2.9 & 33.6 & 63.5 & 2.7 & 30.7 & 66.6 \\
\hline \multicolumn{7}{|l|}{ Caste } \\
\hline General & 3.2 & 34.8 & 62.1 & 2.5 & 32.1 & 65.4 \\
\hline SC & 2.8 & 32.1 & 65.1 & 2.5 & 21.2 & 76.2 \\
\hline ST & 2.5 & 35.1 & 62.4 & 1.2 & 28.1 & 70.7 \\
\hline
\end{tabular}

Source: Sample Survey.

Table 4: Women experiencing different levels of restrictions by husband by migrant status and background characteristics (percentage)

\begin{tabular}{|c|c|c|c|c|c|c|}
\hline \multirow[t]{2}{*}{ Background characteristics } & \multicolumn{3}{|c|}{ Living with husband (non-migrant $\mathrm{HH}$ ) } & \multicolumn{3}{|c|}{ Not living with husband (migrant $\mathrm{HH}$ ) } \\
\hline & Low & Medium & High & Low & Medium & High \\
\hline \multicolumn{7}{|l|}{ Age of women (in years) } \\
\hline 15-19 & 2.3 & 26.5 & 71.2 & 1.4 & 24.6 & 74.0 \\
\hline $20-34$ & 1.8 & 22.4 & 75.7 & 1.6 & 19.1 & 79.4 \\
\hline $35-49$ & 1.8 & 20.7 & 77.5 & 1.1 & 16.4 & 82.6 \\
\hline \multicolumn{7}{|l|}{ Marital duration (in years) } \\
\hline $0-9$ & 1.9 & 21.2 & 76.9 & 2.0 & 16.9 & 81.1 \\
\hline $10-19$ & 2.0 & 22.6 & 75.4 & 1.0 & 17.7 & 81.3 \\
\hline$>20$ & 1.7 & 22.1 & 76.2 & 1.0 & 23.2 & 75.8 \\
\hline \multicolumn{7}{|l|}{ Household structure } \\
\hline Non-nuclear & 2.0 & 22.5 & 75.5 & 1.2 & 18.8 & 80.0 \\
\hline Nuclear & 1.8 & 21.4 & 76.9 & 1.7 & 18.0 & 80.3 \\
\hline \multicolumn{7}{|l|}{ Education of women } \\
\hline No education & 2.3 & 22.6 & 75.1 & 2.3 & 23.2 & 74.5 \\
\hline Primary & 2.1 & 23.8 & 74.1 & 1.5 & 16.3 & 82.2 \\
\hline Secondary & 1.7 & 21.0 & 77.2 & 1.3 & 15.3 & 83.4 \\
\hline Higher & 0.8 & 19.3 & 79.9 & 0.1 & 13.6 & 86.3 \\
\hline
\end{tabular}




\section{Education of husband}

\begin{tabular}{lll} 
No education & 2.0 & 21. \\
Primary & 2.2 & 22. \\
Secondary & 1.9 & 22. \\
Higher & 1.3 & 20.6 \\
Wife currently working & & \\
No & 1.8 & 22. \\
Yes & 2.0 & 21. \\
Standard of living & & \\
Low & 2.4 & 23.8 \\
Medium & 2.0 & 22. \\
High & 1.6 & 20.9 \\
Caste & & \\
General & 1.9 & 24.3 \\
SC & 2.2 & 22.2 \\
ST & 1.7 & 23. \\
OBC & 1.7 & 18.9 \\
\hline
\end{tabular}

Source: Sample Survey.

husbands. Among left-behind wives, rural women have high restrictions compared to their urban counterparts.

\section{CONCLUSION}

Migration is changing the, demographic, socioeconomic and development profile of India. This study suggests an impact on the women who are living absence of her husband. Relatively aged women are more likely to live with their husband or family as compared to younger women. This may be reason the husbands of aged women are settled and can beer to keep their family with them when they migrate, while the husbands of newly married women are still not settled enough to maintain their family with them. Women who belong to the lower standard of living category are left behind due to male out-migration, whereas women belong to the higher standard of living category are mostly living with their male member. But this results need to be highly explored more as data limit for assessing this type of particular circumstances. Women whose husbands have out-migrated tend not to work and this may be reason in the absence of their husband since women's responsibilities regarding their children's health and education, social expectation and dependency on others, increases. Women's greater involvement in agricultural activity and increased responsibility in maintaining households may or may not improve their socio-economic status.
Previous research work in this regard suggests that most of the out-migration takes place from the rural areas of India. Rural unemployment resulting from high population growth and the mordernisation of agricultural activity has been identified as the main cause of out migration from rural areas (UN POPIN 1995).

Another reason that the wives of migrant men may get little time to work outside of the home might be that, in the absence of the husband, the wife has to shoulder the responsibility of taking care of other members of the extended household. Indian society does not readily allow married women to live alone. While this extended household pattern gives social protection to the wife, it may restrain their empowerment if decision-making powers are transferred to other male members.

Women in the society from where male members migrate are likely to assert more authority within the household, including having more decision-making authority regarding child-rearing, household expenditure and healthcare.

It has also been found that women are now managing bank accounts, which is a positive sign of economic emancipation. The findings of this study do not show or break from the traditional patriarchal kinship system persistent in the typical Indian family. The male out migration has not had a significant impact on the women empowerment. The most general factors which increase the mobility of women, decision-making powers and that 
decrease the restrictions placed on them are the age, level of education, marital period, occupation and urban residence of the women in question. The common variable which has an inverse impact on the decision-making powers, the restrictions placed on them and mobility of women is the husband's educational level. However, the findings do not show how factors interact to influence the women empowerment. Despite this limitation, the results will be beneficial in identifying those classes of women where society, policy makers and institutions can direct their endeavours and interventions to ensure a tangible enhancement in women's empowerment.

\section{REFERENCES}

Acosta, P. 2007. Entrepreneurship, labor markets, and international remittances: evidence from El Salvador, II In: Ozden, C and Schiff, M (Eds.), International Migration, Economic Development and Policy. The World Bank and Palgrave Macmillan Publications, New York.

Amin, R., Becker, S. and Bayes A. 1998. NGO promotes microcredit programmes and women's empowerment in rural Bangladesh: Quantitative and qualitative evidence. The Journal of Developing Areas, 32(2): 221 - 236.

Sinha. B. Jha. S. and Negi. N.S. 2012. Migration and empowerment: the experience of women in households in India where migration of a husband has occurred. Journal of Gender Studies, 21(1): 61-76.

Colfer, C. 1985. On circular migration: from the distaff side. In: G. Standing, ed. Labour circulation and the labour process. Croom Helm, 219 - 251.
Deshmukh-Ranadive, J. 2003. Placing gender equity in the family centre stage: use of 'Kala Jatha'theatre. Economic and Political Weekly, 38(17): $1674-1679$.

Duflo, E. 2003. Grandmothers and granddaughters: old age pension and intra-household allocation in South Africa. World Bank Economic Review, 42: 1 - 25.

Gulati, L. 1993. In the absence of their men: the impact of male migration on women. New Delhi/Thousand Oaks/ London: Sage.

Hashemi, S., Schuler, S.R. and Riley, A. 1996. Rural credit programs and women's empowerment in Bangladesh. World development, 24(4): 635-40.

Malhotra, A. and Mather, M. 1997. Do schooling and work empower women in developing countries? Gender and domestic decisions in Sri Lanka. Sociological Forum, 12(4): $599-630$.

Parasuraman, S. 1986. Migration and its effect on the family. Indian Journal of Social Work, 47(1): 1 - 14.

Schuler, S.R. and Hashemi, S.M. 1993. Defining and studying empowerment of women: a research note from Bangladesh. JSI working paper no. 3. Arlington, VA: JSI Research and Training Institute.

Sen, A. 2001. Many faces of gender inequality. Frontline, [online]. Available from: http://www. frontlineonnet.com/ fl1822/18220040.htm

United Nations Populations Information Network (UN POPIN), 1995. Gender, migration, farming systems \& land tenure [online]. Available from http:// www.un.org/ popin/fao/faomod/mod4.html. 
